\title{
ON BEHAVIOUR OF THE RIESZ AND GENERALIZED RIESZ POTENTIALS AS ORDER TENDS TO ZERO
}

\author{
A. D. Gadjiev, A. Aral and Ilham A. Aliev
}

Abstract. In this paper, we present the Riesz potentials $I^{\alpha}$ and the generalized Riesz potentials $I_{v}^{\alpha}$ as the families of positive linear operators, depending on parameter $\alpha>0$. We investigate their pointwise convergence and convergence in the norm as $\alpha \rightarrow 0$. We investigate also the order of approximation of these families and show in particular that the order of approximation at the Lipschitz points is independent from Lipschitz degree.

Mathematics subject classification (2000): 41A35, 26 A33.

Key words and phrases: Riesz potentials, generalized translation operator, d-point, Lipschitz point, approximation, modulus of continuity.

\section{REFERENCES}

[1] I. A. AliEv AND B. RuBIn, Parabolic potentials and wavelet transforms with the generalized translation, Studia Math. 145 (1) (2001), 1-16.

[2] I. A. ALIEV AND B. RUBIN, Wavelet-like transforms for admissible semi-groups; inversion formulas for potentials and Radon transforms, The Journal of Fourier Analysis and Applications, 11 (3) (2005), 334-352.

[3] A. ARAL, On generalized potential-type integral operators with non-isotropic kernel, Intern. Math. Journal, Vol 3, (2003), No:12, 1367-1378.

[4] A. D. GADJIEV AND I. A. AliEV, On classes of operators of potential type, generated by a generalized shift, Reports of enlarged session of the I. N. Vekua Inst. of Applied Mathematics, 3, N2, Tbilisi, 1988 (in Russian).

[5] A. D. GadjIEV And I. A. Aliev, Riesz and Bessel potentials generated by the generalized translation and their inverses, Proc. IV All-Union Winter Conf. "Theory of functions and approximation", Saratov (Russia)-1988; In the book "Theory of functions and approximation", Printed in Saratov University (1990), 47-53 (in Russian).

[6] V. S. Guliev, Sobolev theorem for the B-Riesz potentials, Dokl. Rus. Akad. Nauk (RAN), 358 (4) (1998), 450-451 (in Russian).

[7] I. A. KIPRIYANOV, Singular Elliptic Boundary Problems, Nauka, Moscow, Fizmatlit, 1997 (in Russian).

[8] T. KuroKawa, On the Riesz and Bessel kernels as approximations of the identity, Sci. Rep. Kagoshima Univ., No:30(1981), 31-45.

[9] B. M. LEVITAN, Expansion in Fourier series and integrals in Bessel functions, Uspekhi. Matem. Nauk, 6 (2) (1951), 102-143 (in Russian).

[10] J. LÖFSTRÖM AND J. PEETRE, Approximation theorems connected with generalized translation, Math. Ann., 181 (1969), 255-268.

[11] B. RuBIN, Fractional Integrals and Potentials, Pitman Monograps and Surveys in Pure and Appl. Math., 82, Longman, Harlow, 1996.

[12] S. G. SAmko, A. A. Kilbas And O. I. Marichev, Fractional Integrals and Derivatives, Theory and Applications. Gordon and Breach Science Publishers, 1993.

[13] E. STEIN, Singular Integrals and Differentiability Properties of Functions, Princeton Univ. Press, Princeton, N. J., 1970. 
[14] K. STEMPaK, La theorie de Littlewood-Paley pour la transformation de Fourier-Bessel, C. R. Acad. Sci. Paris, ser. I (303) (1986), 15-18.

[15] A. F. Timan, Theory of Approximation of Functions of a Real Variable, New York, 1963.

[16] K. TRIMÉchE, Generalized Wavelets and Hypergroups, Gordon and Breach Science Publishers, (1997). 